\title{
Safety and efficacy of Becaplermin gel in the treatment of diabetic foot ulcers
}

This article was published in the following Dove Press journal:

Chronic Wound Care Management and Research

29 July 2014

Number of times this article has been viewed

\author{
Peter Blume' \\ Melinda Bowlby ${ }^{2}$ \\ Brian M Schmidt ${ }^{2}$ \\ Ryan Donegan ${ }^{2}$ \\ 'Orthopedics and Rehabilitation, \\ and Anesthesia, Yale School of \\ Medicine, ${ }^{2}$ Section of Podiatric \\ Surgery, Department of Orthopedics \\ and Rehabilitation, Yale New Haven \\ Hospital, New Haven, CT, USA
}

\begin{abstract}
Becaplermin gel remains the only US Food and Drug Administration (FDA)-approved growth factor for the treatment of diabetic neuropathic foot ulcers. Becaplermin gel has shown to be efficacious in a number of clinical trials. The FDA has added a black box warning label about the risk of cancer associated with the use of three or more Becaplermin tubes. Other adverse drug reactions associated with Becaplermin gel use are minimal. There is a need for further research regarding the true correlation between cancer and Becaplermin gel use.
\end{abstract}

Keywords: diabetic, ulcer, wound care, advanced biologic therapy

\section{Introduction}

Diabetes mellitus remains the seventh leading cause of death in the United States. ${ }^{1}$ In the United States, 25.8 million people, comprising $8.3 \%$ of the population, are affected by diabetes. ${ }^{1}$ A large portion of these deaths are related to diabetic foot ulcers, which ultimately result in infection. ${ }^{2}$ Diabetic peripheral neuropathy and ischemia, along with a number of other metabolic derangements, predispose the diabetic patient to developing a foot ulcer and also, prolong the rate of healing. ${ }^{2}$ Of those that develop diabetic foot ulcers, it is roughly estimated that $20 \%$ will require an amputation. ${ }^{3}$ Traditional wound care efforts include offloading, sharp debridement of nonviable tissue, and restoring adequate perfusion. ${ }^{4}$

In 2003, Sheehan et al changed the expectations of standard wound care. Their study included 203 diabetic foot ulcers, and of those that had at least 53\% reduction in 4 weeks, $58 \%$ healed. ${ }^{5}$ If the reduction was less than $53 \%$, only $9 \%$ healed over 12 weeks. ${ }^{5}$ Health care practitioners are now looking for reduction of wound size by approximately $50 \%$ within 4 weeks. The goal of wound care is now, not only to heal wounds, but also, to do so expeditiously. With this expectation, hyperbaric oxygen therapy, bioengineered skin substitutes, extracellular matrix proteins, and growth factors have been developed to expedite the slow healing process seen in diabetic foot ulcers. ${ }^{4}$

\section{History of Becaplermin gel}

Becaplermin gel (Regranex ${ }^{\circledR}$; Smith \& Nephew, Inc., London, UK) was first approved by the US Food and Drug Administration (FDA) in 1997 for treatment of diabetic neuropathic foot ulcers. ${ }^{6}$ Becaplermin gel is recombinant platelet-derived growth factor (PDGF)-BB produced by insertion of the gene into yeast Saccharomyces cerevisiae. ${ }^{6} \mathrm{~A}$ previous study has proven endogenous PDGF to play an important 
role in wound healing. ${ }^{3}$ Endogenous PDGF is produced by platelets, macrophages, endothelial cells, fibroblasts, and keratinocytes. ${ }^{3}$ PDGF induces chemotaxis of cells, including neutrophils, macrophages, and fibroblasts, to the wound and promotes fibroblast and collagen production. ${ }^{3}$ Furthermore, PDGF signals collagen remodeling and crosslinking. ${ }^{3}$

Becaplermin gel has been shown to promote wound healing in a number of studies, as shown in Table $1 .{ }^{6}$ Becaplermin gel remains one of three biologics that is currently FDAapproved for the treatment of diabetic foot ulcers and is the only FDA-approved growth factor. ${ }^{6}$ Becaplermin gel has also become one of the most controversial advanced wound care products, due to the black box warning applied by the FDA in 2009 , cautioning about the risk of potential malignancy. ${ }^{6}$

\section{Use}

The amount of Becaplermin gel per application is calculated by the ulcer size, as (length in $\mathrm{cm} \times$ width in $\mathrm{cm}$ ) $/ 0.4 .^{7}$ Becaplermin gel $0.01 \%$ is distributed in a $15 \mathrm{~g}$ tube, and it is recommended that the amount per application be recalculated weekly by the health care provider. ${ }^{7}$ The Becaplermin gel product insert recommends that if there is not a 30\% decrease in size after 10 weeks or complete healing in 20 weeks, the health care provider should consider the risks and benefits of continuing Becaplermin gel. ${ }^{7}$ Becaplermin gel should be applied once daily, followed by application of a salinemoistened gauze, which should be changed twice daily. ${ }^{7}$

\section{Indications and contraindications}

Becaplermin gel is indicated for full-thickness diabetic neuropathic ulcers of the lower extremity that have adequate perfusion. ${ }^{7}$ Becaplermin gel is not indicated with venous stasis, or ischemic or decubitus ulcers. ${ }^{7}$ Becaplermin gel is also not indicated for use on tendon, bone, or ligaments, and application to these sites is considered off-label use. ${ }^{7}$ Likewise, Becaplermin gel is not indicated for surgical wounds that are closed primarily. ${ }^{7}$ Becaplermin gel is contraindicated in patients with malignancy at the application site, and caution is urged with patients who have a known malignancy. ${ }^{7}$ Like many drugs, use in pregnant women, nursing mothers, and children has not been tested. ${ }^{7}$

\section{Efficacy}

Six studies were performed in clinical trials that led to the FDA approval of Becaplermin gel. ${ }^{8}$ Since then, a number of other studies have been reported.

In 1998, Wieman et al published a double-blinded, parallel group study of 382 patients. ${ }^{9}$ Moist saline dressings were changed twice daily, and patients applied either Becaplermin gel or placebo gel to their ulcers daily for 20 weeks or until the ulcer healed. Offloading and ulcer debridement were used in conjunction. ${ }^{9}$ Complete healing was observed in $50 \%$ (61 of 123 ) of patients who received Becaplermin gel $100 \mu \mathrm{g}$ compared with $36 \%$ (48 out of 132) of patients who were treated with Becaplermin gel $30 \mu \mathrm{g}$, and 35\% (44 out of 132) who were treated with the placebo. ${ }^{9}$

One of the most powerful studies was conducted in 1999, when Smiell et al published an analysis of four previously published studies, each of 20-weeks duration, comparing results of patients with diabetic foot ulcers treated with either Becaplermin $30 \mu \mathrm{g}$ gel with wound care, Becaplermin $100 \mu \mathrm{g}$ gel with wound care, placebo gel and wound care, or wound care alone. ${ }^{10}$ Combined, these studies included 922 patients, and $50 \%$ healed among those treated with Becaplermin $100 \mu \mathrm{g}$ gel, $42 \%$ healed among those treated with Becaplermin $30 \mu \mathrm{g}$ gel, 36\% healed among those treated with the placebo gel, and $36 \%$ healed among patients treated with wound care alone. ${ }^{10}$

Table I Efficacy of Becaplermin

\begin{tabular}{|c|c|c|c|c|}
\hline Study & $\begin{array}{l}\text { Study size (number } \\
\text { of patients) }\end{array}$ & $\begin{array}{l}\text { Percent healed } \\
\text { (Becaplermin) }\end{array}$ & Percent healed (control) & Trial design \\
\hline Wieman et al ${ }^{9}$ & 382 & $\begin{array}{l}50 \% \text { of patients treated with } \\
\text { Becaplermin gel } 100 \mu \mathrm{g} \\
36 \% \text { of patients treated with } \\
\text { Becaplermin gel } 30 \mu \mathrm{g}\end{array}$ & $\begin{array}{l}35 \% \text { of patients treated } \\
\text { with the placebo }\end{array}$ & $\begin{array}{l}\text { Double-blinded, } \\
\text { placebo-controlled }\end{array}$ \\
\hline Embil et al' & 134 & $\begin{array}{l}57.5 \% \text { had complete healing } \\
23 \% \text { had marked improvement } \\
\text { of } 51 \%-99 \% \text { closure }\end{array}$ & No control & Phase IIIB open-label \\
\hline Margolis et $\mathrm{al}^{12}$ & 2,394 & $\begin{array}{l}33.5 \% \text { treated with } \\
\text { Becaplermin gel }\end{array}$ & $\begin{array}{l}25.8 \% \text { of patients who were } \\
\text { treated with another agent }\end{array}$ & Cohort study \\
\hline Smiell et al $^{10}$ & 922 & $\begin{array}{l}50 \% \text { of patients treated with } \\
\text { Becaplermin } 100 \mu g \text { gel } \\
42 \% \text { of patients treated with } \\
\text { Becaplermin } 30 \mu \mathrm{g} \text { gel }\end{array}$ & $\begin{array}{l}36 \% \text { of patients treated with } \\
\text { the placebo gel } \\
36 \% \text { of patients treated with } \\
\text { wound care alone }\end{array}$ & Meta-analysis \\
\hline
\end{tabular}


Embil et al published a study, in 2000, of 134 patients with diabetic foot ulcers that were treated with Becaplermin gel. ${ }^{11}$ Becaplermin gel was applied daily for a maximum of 20 weeks or until the wound healed. ${ }^{11}$ Offloading with an Aircast ${ }^{\circledR}$ apparatus (DJO, LLC, Vista, CA, USA), biweekly sharp debridement, and application of Adaptic ${ }^{\circledR}$ Non-Adhering Dressing (Systagenix, Gatwick, UK) were used in conjunction with Becaplermin gel. ${ }^{11}$ The researchers found that $57.5 \%(77 / 134)$ of patients had complete healing in a mean of 63 days, and an additional $23 \%$ had marked improvement, with $51 \%-99 \%$ wound closure. ${ }^{11}$

Margolis et al published a cohort study in 2005 of 2,394 patients being treated with Becaplermin gel for diabetic foot ulcers. ${ }^{12}$ During the 20 weeks of observation, $802(33.5 \%)$ patients who were treated with Becaplermin gel healed compared with 5,806 (25.8\%) patients who were not treated with Becaplermin gel. ${ }^{12}$

In 2009, Bhansali et al published a study comparing standard wound care and use of Becaplermin gel in 17 patients offloaded with a total contact cast for 20 weeks or until the ulcer healed. ${ }^{13}$ All ulcers healed in both groups; however, the group treated with Becaplermin gel healed faster. ${ }^{13}$ The group treated with Becaplermin healed in an average of 50.10 days compared with the standard wound care group for whom healing occurred in an average of 86.10 days. ${ }^{13}$

Becaplermin gel's efficacy has been demonstrated in numerous studies; however, less studied is its comparison with or its use in combination with other biological agents. Kirsner et al published a retrospective cohort study, in 2010, comprising 2,517 patients with diabetic foot ulcers that were treated with an advanced biologic therapy, including Becaplermin gel, bilayered living cell therapy (Apligraf ${ }^{\mathbb{B}}$; Organogenesis Inc., Canton, MA, USA), platelet releasate (Procuren ${ }^{\circledR}$; Cytomedix, Gaithersburg, MD, USA), or Becaplermin gel, or Procuren followed by Apligraf. ${ }^{14}$ They found that wounds first treated with Apligraf were 31.2\% more likely to heal than wounds first treated with Becaplermin gel and $40.0 \%$ more likely to heal than those first treated with Procuren. ${ }^{14}$ They also found that the median time necessary for wound healing was 6 weeks for Apligraf, 4 weeks for Procuren, and 3 weeks for Becaplermin gel. ${ }^{14}$

In 2010 Landsman et al studied the treatment of 32 diabetic foot ulcers with either Becaplermin gel and Theragauze ${ }^{\circledR}$ (Soluble Systems LLC, Newport News, VA, USA), Theragauze alone, or saline-soaked gauze and Becaplermin gel alone for 20 weeks. ${ }^{15}$ They found that $69.2 \%$ of wounds in the Becaplermin gel and Theragauze group healed compared to $61.5 \%$ of the wounds in the Theragauze alone group. ${ }^{15}$

\section{Safety and clinical advisories}

In animal clinical trials, a nominal amount of Becaplermin gel was found to be systemically bioavailable, with less than a $3 \%$ measurable accumulation of PDGF. ${ }^{8}$ In humans no elevation above the normal plasma PDGF level was found. ${ }^{8}$

Becaplermin gel has been associated with an increased risk of cancer. In two randomized, controlled trials of 651 subjects, 491 (75\%) were followed for approximately 20 months after treatment with Becaplermin gel. ${ }^{7}$ Researchers found that $3 \%$ of the Becaplermin gel group (eight out of 291 patients) compared with 1\% (two out of 200 patients) of the standard care group were diagnosed with cancers, which were distant from the treatment site. ${ }^{7}$ No particular malignancy was associated with Becaplermin gel use. ${ }^{6}$

A retrospective analysis of the cancer incidence and mortality rates of 1,622 patients who used Becaplermin gel and 2,809 comparative patients was performed from a medical claims database. ${ }^{7}$ Patients treated with Becaplermin gel had a cancer incidence of 10.2 per 1,000 , and the mortality rate was 1.6 per 1,000 people. $^{7}$ In the comparative patient group, the rate of developing cancer was 9.1 per 1,000, and the mortality rate was 0.9 per 1,000 people. $^{7}$ Patients treated with three or more tubes of Becaplermin gel had a mortality rate of 3.9 per 1,000 person years compared with 0.9 per 1,000 person years in the comparative patient group. ${ }^{7}$ In 2009, the FDA added a black box warning label about the risk of cancer associated with the use of three or more Becaplermin gel tubes. ${ }^{6}$

It is important to mention that there is a higher prevalence of cancer among diabetic patients. The hyperglycemia, hyperinsulinemia, and chronic inflammation found in patients with diabetes mellitus are proposed mechanisms that may explain the increased rate of malignacy. ${ }^{16}$ According to a study by Li et al, diabetic men had a higher prevalence ratio for cancers of the prostate (1.1), colon (1.3), pancreas (4.6), rectum (2.2), urinary bladder (1.7), and kidney (1.9) than men not diagnosed with diabetes. ${ }^{16}$ The same study showed that diabetic women had higher prevalence ratios for cancers of the breast (1.1), endometrium (1.6), and leukemia (2.3) than women not diagnosed with diabetes. ${ }^{16}$ The correlation of increased cancer with use of Becaplermin in the treatment of diabetic foot ulcers may be due to diabetes rather than the use of Becaplermin. Since Becaplermin is approved for diabetic foot ulcers, it would be difficult to study it in other patient populations.

Other minimal side effects included erythematous rashes in $2 \%$ of patients treated with Becaplermin gel in clinical trials (as seen in Figure 1). ${ }^{7}$ In the Wieman et al study, 43 experienced adverse events consisting of cellulitis, 


\begin{tabular}{|l|}
\hline Erythematous rash \\
\hline Cellulitis \\
\hline Osteomyelitis \\
\hline Pain \\
\hline Edema \\
\hline Infection \\
\hline Skin disorder \\
\hline
\end{tabular}

Figure I Reported adverse drug events with use of Becaplermin gel.

osteomyelitis, pain, edema, infection, or skin disorder (as listed in figure 1). ${ }^{9}$ Most adverse events were related to the underlying condition, and occurrences were similar in the Becaplermin gel group and the placebo group. ${ }^{9}$

\section{Conclusion}

Many studies have illustrated the efficacy of Becaplermin gel, but clearly there is an indication for retrospective cohort studies following patients and incidence of cancer over a long-term. In humans, no amount of Becaplermin gel has been found to be systemically available, and no study has reported a patient developing malignancy at the site where Becaplermin gel was used, to the authors' knowledge. ${ }^{8}$

Currently the black box warning regarding the correlation between cancer and Becaplermin gel use is speculative as there is increased malignancy in diabetic populations. ${ }^{16}$ Further research is needed to compare the use of Becaplermin gel with other available biologics and skin substitutes. After a better understanding is reached regarding the risks, the patient and health care provider may decide whether the risks are worth the reward. ${ }^{6}$

\section{Disclosure}

The authors report no conflicts of interest in this work.

\section{References}

1. Centers for Disease Control and Prevention. National Diabetes Fact Sheet: National Estimates and General Information on Diabetes and Prediabetes in the United States, 2011. Atlanta, GA: US Department of Health and Human Services, Centers for Disease Control and Prevention; 2011.
2. Fang RC, Galiano RD. A review of becaplermin gel in the treatment of diabetic neuropathic foot ulcers. Biologics. 2008;2(1):1-12.

3. Nagai MK, Embil JM. Becaplermin: recombinant platelet derived growth factor, a new treatment for healing diabetic foot ulcers. Expert Opin Biol Ther. 2002;2(2):211-218.

4. Papanas N, Maltezos E. Becaplermin gel in the treatment of diabetic neuropathic foot ulcers. Clin Interv Aging. 2008;3(2):233-240.

5. Sheehan P, Jones P, Caselli A, Giurini JM, Veves A. Percent change in wound area of diabetic foot ulcers over a 4-week period is a robust predictor of complete healing in a 12 -week prospective trial. Diabetes Care. 2003;26(6):1879-1882.

6. Papanas N, Maltezos E. Benefit-risk assessment of becaplermin in the treatment of diabetic foot ulcers. Drug Saf. 2010;33(6):455-461.

7. Regranex ${ }^{\circledR}$ Gel (becaplermin) [package insert]. London: Smith and Nephew Inc.; 2012. Available from: http://www.regranex.com/pdf/ PI_Full_Version.pdf. Accessed February 3, 2014.

8. Becaplermin [approval letter]. Rockville, MD: US Food and Drug Administration, Center for Drug Evaluation and Research; 1997. Available from: http://www.fda.gov/Drugs/DevelopmentApprovalProcess/ HowDrugsareDevelopedandApproved/ApprovalApplications/ TherapeuticBiologicApplications/ucm080740.htm. Accessed February 3, 2014.

9. Wieman TJ, Smiell JM, Su Y. Efficacy and safety of a topical gel formulation of recombinant human platelet-derived growth factor-BB (becaplermin) in patients with chronic neuropathic diabetic ulcers. A phase III randomized placebo-controlled double-blind study. Diabetes Care. 1998;21(5):822-827.

10. Smiell JM, Wieman TJ, Steed DL, Perry BH, Sampson AR, Schwab BH. Efficacy and safety of becaplermin (recombinant human platelet-derived growth factor-BB) in patients with nonhealing, lower extremity diabetic ulcers: a combined analysis of four randomized studies. Wound Repair Regen. 1999;7(5):335-346.

11. Embil JM, Papp K, Sibbald G, et al. Recombinant human plateletderived growth factor-BB (becaplermin) for healing chronic lower extremity diabetic ulcers: an open-label clinical evaluation of efficacy. Wound Repair Regen. 2000;8(3):162-168.

12. Margolis DJ, Bartus C, Hoffstad O, Malay S, Berlin JA. Effectiveness of recombinant human platelet-derived growth factor for the treatment of diabetic neuropathic foot ulcers. Wound Repair Regen. 2005;13(6): 531-536.

13. Bhansali A, Venkatesh S, Dutta P, Dhillon MS, Das S, Agrawal A. Which is the better option: recombinant human PDGF-BB $0.01 \%$ gel or standard wound care, in diabetic neuropathic large plantar ulcers off-loaded by a customized contact cast? Diabetes Res Clin Pract. 2009;83(1):e13-e16.

14. Kirsner RS, Warriner R, Michela M, Stasik L, Freeman K. Advanced biological therapies for diabetic foot ulcers. Arch Dermatol. 2010;146(8):857-862.

15. Landsman A, Agnew P, Parish L, Joseph R, Galiano RD. Diabetic foot ulcers treated with becaplermin and TheraGauze, a moisture-controlling smart dressing: a randomized, multicenter, prospective analysis. $J \mathrm{Am}$ Podiatr Med Assoc. 2010;100(3):155-160.

16. Li, Balluz LS, Ford ES, Okoro CA, Tsai J, Zhao G. Association between diagnosed diabetes and self-reported cancer among US adults: findings from the 2009 Behavioral Risk Factor Surveillance System. Diabetes Care. 2011;34(6):1365-1368.

\section{Publish your work in this journal}

Chronic Wound Care Management and Research is an international, peer reviewed, open access, online journal publishing original research, reviews, editorials, and commentaries on the causes and management of chronic wounds and the major issues related to chronic wound management. Topics also include chronic wounds as comorbidities to other

\section{Dovepress}

conditions, patient adherence to therapy, and the economic burden of chronic wounds. The manuscript management system is completely online and includes a very quick and fair peer review system, which is all easy to use. Visit http://www.dovepress.com/testimonials.php to read real quotes from published authors. 